\title{
DEVELOPMENT OF A RECIRCULATING CONVEYANCE SYSTEM TO FACILITATE SPOT APPLICATION OF DICHLOBENIL
}

\author{
Craig MacEachern ${ }^{1 *}$, Travis Esau ${ }^{1}$, Scott White ${ }^{2}$, Qamar Zaman ${ }^{1}$, Aitazaz Farooque ${ }^{3}$ \\ ${ }^{1}$ Department of Engineering, Dalhousie University, Truro, Canada \\ ${ }^{2}$ Department of Plant, Food and Environmental Sciences, Dalhousie University, Truro, Canada \\ ${ }^{3}$ Department of Engineering, University of Prince Edward Island, Charlottetown, Canada \\ *maceachernc@dal.ca
}

\begin{abstract}
To facilitate spot application of dichlobenil (Casoron ${ }^{\circledR} G-4$ ) granular herbicide, a recirculating conveyance system is being developed and implemented on an existing Valmar 1255 broadcast applicator. As the product will need to be repeatedly cycled through the system, the project relies on Casoron ${ }^{\circledR}$ G-4's ability to maintain its size and shape while being cycled. To evaluate Casoron ${ }^{\circledR} G-4$ 's granule robustness, the product was pneumatically cycled for one hour and the change in bulk density was evaluated. From this evaluation, it was determined that there was no significant difference in bulk density ( $p$-value $=0.365)$ indicating that there was no significant granule breakdown. Being that the Valmar applicator already incorporates a pneumatic delivery system, it will only require modification to allow the product to cycle back into the hopper. Further testing is needed to determine the optimal hose sizing and pressures required by the system. Following this, a deflector plate will need to be designed to ensure that the proper granule spread is attained at ground level to ensure even product dispersion. Once the system has been developed and tested at lab scale the plan will be to incorporate it with a machine vision system to facilitate spot application of Casoron ${ }^{\circledR} G-4$ for fescue grass management in wild blueberries. That said the final system should be easily adaptable to a variety of alternative cropping systems.
\end{abstract}

